\title{
Straight deep hypothermic circulatory arrest for cerebral protection during aortic arch surgery: Safe and effective
}

\author{
Bulat A. Ziganshin, MD, ${ }^{\mathrm{a}, \mathrm{b}}$ Bijoy G. Rajbanshi, MD, ${ }^{\mathrm{a}, \mathrm{c}}$ Maryann Tranquilli, RN, ${ }^{\mathrm{a}}$ Hai Fang, PhD, MPH, ${ }^{\mathrm{d}}$ \\ John A. Rizzo, $\mathrm{PhD},{ }^{\mathrm{a}, \mathrm{e}}$ and John A. Elefteriades, $\mathrm{MD}^{\mathrm{a}}$
}

Objective: To evaluate our extensive clinical experience using deep hypothermic circulatory arrest (DHCA) as a sole method of cerebral protection during aortic arch surgery, with an emphasis on determining the safe duration of DHCA.

\begin{abstract}
Methods: A total of 490 consecutive patients (303 males [61.8\%], mean age, $62.7 \pm 13.5$ years) underwent surgical interventions on the aortic arch with straight DHCA for cerebral protection. Of the procedures, $65(13.3 \%)$ were either urgent or emergency. Aortic aneurysms $(\mathrm{n}=417,85.1 \%)$ and dissections $(\mathrm{n}=71$, $14.5 \%)$ were the main indications for surgery.

Results: The mean DHCA duration was $29.2 \pm 7.9$ minutes at a mean bladder temperature of $18.7^{\circ} \mathrm{C}$. The overall mortality was $2.4 \%$ (12 of 490), and elective mortality was $1.4 \%$ ( 6 of 425$)$. The seizure rate was $1.4 \%$ (7 of 490). Six patients (1.2\%) developed renal failure that required dialysis. The postoperative stroke rate was $1.6 \%$ ( 8 of 490$)$ and was $1.2 \%$ (5 of 425 ) for the elective cases. The overall stroke rate for patients requiring $<50$ minutes of DHCA was $1.3 \%$ (6 of 478), significantly different from the $16.7 \%$ (2 of 12 ) stroke rate for patients requiring $>50$ minutes of DHCA $(P=.014)$. Multivariate analysis revealed a DHCA time $>50$ minutes (odds ratio, $5.11 \pm 4.01, P=.038$ ) and aortic dissection (odds ratio, $3.59 \pm 1.72, P=.008$ ) to be strong predictors of composite adverse outcomes.

Conclusions: Straight DHCA is a safe and effective technique of cerebral protection for the absolute majority of interventions involving the aortic arch. At experienced centers, up to 50 minutes of DHCA can be considered safe, without significant postoperative mortality or neurologic sequelae. (J Thorac Cardiovasc Surg 2014;148:888-900)
\end{abstract}

De Bakey and colleagues ${ }^{1,2}$ performed the first successful surgical arch replacement procedure and subsequently reported a mortality rate of $42 \%$ for the first series of arch replacements. Since those early days, the focus of research in this area has aimed at improving surgical techniques and methods of cerebral protection. Cerebral protection has always been a cornerstone of successful arch surgery, although to date, no consensus has been reached regarding the optimal technique for protecting the brain. ${ }^{3-5}$

From the Aortic Institute at Yale-New Haven Hospital, ${ }^{a}$ Yale University School of

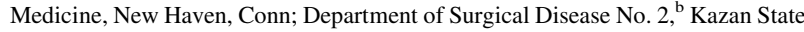
Medical University, Kazan, Russia; Department of Cardiovascular Surgery, ${ }^{c}$ Shahid Gangalal National Heart Center, Bansbari, Kathmandu, Nepal; China Center for Health Development Studies, ${ }^{\mathrm{d}}$ Peking University, Beijing, China; and Departments of Economics and Preventive Medicine, ${ }^{\mathrm{e}}$ Stony Brook University, Stony Brook, NY.

Disclosures: John Elefteriades reports consulting fees for Cryolife, Covidien, and Datascope, equity ownership in Coolspine, and grant support from the National Marfan Foundation. John Rizzo reports consulting fees from CTI clinical trial and consulting and LIP. All other authors have nothing to disclose with regard to commercial support.

Read at the 94th Annual Meeting of The American Association for Thoracic Surgery, Toronto, Ontario, Canada, April 26-30, 2014.

Received for publication April 9, 2014; revisions received May 2, 2014; accepted for publication May 12, 2014; available ahead of print July 19, 2014.

Address for reprints: John A. Elefteriades, MD, Aortic Institute at Yale-New Haven Hospital, Yale University School of Medicine, 789 Howard Ave, Clinic Bldg CB317, New Haven, CT 06510 (E-mail: john.elefteriades@yale.edu).

0022-5223/\$36.00

Copyright (c) 2014 by The American Association for Thoracic Surgery

http://dx.doi.org/10.1016/j.jtcvs.2014.05.027
Historically, hypothermia was the first method of cerebral protection that was used in arch surgery. Initially proven effective for cardiac procedures by Meshalkin in Siberia in the $1950 \mathrm{~s},{ }^{6}$ deep hypothermic circulatory arrest (DHCA) was introduced into clinical practice for aortic arch surgery by Griepp and associates. 78

Hypothermia provides neuroprotection by significantly decreasing the global cerebral metabolic rate for glucose and oxygen. ${ }^{9}$ Hypothermia also significantly reduces temperature-dependent release and extracellular levels of excitatory neurotransmitters such as glutamate, inhibits the pro-apoptotic activity, and reduces the levels of free radicals and inflammatory cytokines. ${ }^{10}$

Clinically, Svensson and colleagues ${ }^{11}$ showed DHCA to be safe and effective for aortic arch surgery in a large patient series. Our group previously reported the safety and effectiveness of DHCA in a series that included both ascending/arch and descending/thoracoabdominal procedures. ${ }^{12}$ More recently, however, with the increasing popularity of adjunctive cerebral perfusion strategies (ie, antegrade $[\mathrm{ACP}]$ and retrograde cerebral perfusion [RCP]), the safety and effectiveness of straight DHCA as the sole method of cerebral protection for surgery of the aortic arch has been questioned. ${ }^{13,14}$ In particular, the question regarding the DHCA duration that can be considered safe has been debated. Several published reports have suggested that a DHCA time of $>20$ to 25 

Abbreviations and Acronyms
$\mathrm{ACP}=$ antegrade cerebral perfusion
$\mathrm{CPB}=$ cardiopulmonary bypass
$\mathrm{DHCA}=$ deep hypothermic circulatory arrest
$\mathrm{OR}=$ odds ratio
$\mathrm{RCP} \quad=$ retrograde cerebral perfusion

minutes will result in adverse outcomes and poor quality of life postoperatively in patients undergoing thoracic aortic surgery. ${ }^{15,16}$ However, this is not in line with our experience using DHCA. Therefore, the aim of the present study was to evaluate our extensive experience using DHCA as a sole means of cerebral protection during surgery of the aortic arch, with an emphasis on determining the safe duration of DHCA. We found that straight DHCA is a safe and effective technique of cerebral protection for the absolute majority of interventions involving the aortic arch that can be performed within a safe 50 minutes of DHCA.

\section{METHODS}

\section{Patient Profile}

During the previous 11-year period, from January 2003 until September 2013, 490 consecutive patients (mean age, $62.7 \pm 13.5$ years, 303 males, 187 females) underwent surgical interventions on the aortic arch by a single surgeon at Yale-New Haven Hospital (New Haven, Conn). In all 490 cases, straight DHCA was the sole method of cerebral protection; no adjunct perfusion techniques were used. These patients were included in the present study, and a detailed retrospective medical record analysis of these patients was performed.

The preoperative characteristics are presented in Table 1. The indications for surgery included aortic aneurysm in $417(85.1 \%)$, aortic dissection in 71 $(14.5 \%)$, which included acute aortic syndromes (penetrating aortic ulcer and intramural hematoma), and atheroma of the aortic arch in $2(0.4 \%)$. Of the procedures, $65(13.3 \%)$ were either urgent or emergency; all other procedures were performed electively. Seventy-one patients $(14.5 \%)$ had undergone previous cardiac surgery, including 3 patients $(0.6 \%)$ with previous heart transplants. Sixty-five patients (13.3\%) had undergone previous aortic surgery, involving the aortic valve $(\mathrm{n}=42,8.6 \%)$, ascending aorta $(\mathrm{n}=28,5.7 \%)$, aortic arch $(\mathrm{n}=2,0.4 \%)$, descending or thoracoabdominal aorta $(\mathrm{n}=6$, $1.2 \%)$, or abdominal aorta $(\mathrm{n}=2,0.4 \%$; multiple previous sites in some cases). The extent of surgical intervention included replacement of the ascending aorta and hemiarch in 392 patients $(80.0 \%)$, replacement of the ascending aorta and total arch in $74(14.5 \%)$, total replacement of the aortic arch in $13(2.7 \%)$, and repair of the aortic arch in 11 patients $(2.2 \%)$.

\section{DHCA Technique}

Our preferred technique of conducting DHCA has been previously described in detail. ${ }^{6,12,17}$ The main points are as follows:

1. Establishment of cardiopulmonary bypass (CPB): the femoral artery is our preferred site for arterial cannulation to establish CPB during interventions on the ascending aorta and aortic arch (technique described previously ${ }^{18}$ ). Femoral cannulation was used in 390 patients (79.6\%). In cases in which arteriosclerotic disease of the descending aorta was noted by intraoperative transesophageal echocardiography or preoperative computed tomography (routinely performed for patients undergoing elective surgery), we used axillary cannulation $(\mathrm{n}=49,10.0 \%)$, direct cannulation of the ascending aorta/aortic arch $(n=46,9.4 \%)$, or cannulation of the innominate artery $(n=5,1.0 \%)$. Venous return was achieved via the right atrial appendage using a 2-stage cannula $(\mathrm{n}=485,99.0 \%)$ or, in rare cases, via the femoral vein $(\mathrm{n}=5,1.0 \%)$.

2. Topical cooling: the patient's head is packed in ice to achieve topical cooling from the start of the procedure until the end of the circulatory arrest.

3. Systemic cooling: after initiation of $\mathrm{CPB}$, the patient is cooled down to $20^{\circ} \mathrm{C}$ (for hemiarch procedures) or $18^{\circ} \mathrm{C}$ (for total arch replacements). Cooling to the target temperatures require about 30 to 40 minutes, depending on the patient's size.

4. Temperature monitoring: temperature monitoring is conducted solely via a probe in the urinary bladder.

5. Anesthetic considerations: steroids are routinely administered for all patients before CPB is initiated. Alpha-stat management is used routinely to maintain the acid-base balance.

6. Rewarming: once circulatory arrest has been terminated, rewarming is initiated, requiring approximately 60 minutes (also dependent on patient size). We prefer gentle rewarming (gradient between blood and bath temperature of $<10^{\circ} \mathrm{C}$ ) to prevent potential protein denaturation. Rewarming is taken to a temperature of $34^{\circ}$ to $36^{\circ} \mathrm{C}$.

\section{DHCA Duration}

The mean DHCA duration was $29.2 \pm 7.9$ minutes at a mean bladder temperature of $18.7^{\circ} \mathrm{C}$. Of the 490 patients, $61(12.4 \%)$ required a DHCA time of $>40$ minutes; only 12 patients $(2.4 \%)$ required $\geq 50$ minutes (Figure 1 shows the DHCA time distribution).

\section{Operative Technique}

All surgical interventions were performed through a standard median sternotomy with the use of CPB and DHCA. Detailed operative data are presented in Table 2. Carbon dioxide flooding of the surgical field was used in all cases. The extent of surgical resection depends on the disease extent to excise all severely dilated segments of the aorta. Once the patient has been cooled and circulatory arrest initiated, the aorta is unclamped and distal anastomosis performed. In patients requiring total arch replacement, the distal anastomosis is performed at the level of the proximal descending aorta or at the level just before take off of the left subclavian artery. In most cases, this was combined with the elephant trunk procedure. The arch vessels were then reconstructed, either using the "island" technique or by anastomosing each branch with individual grafts. Our preferred technique has been to use a 2 -vessel patch (including the innominate artery and left common carotid artery), which is anastomosed to the main graft (Figure 2,B). The left subclavian artery is reconstructed at a later stage, often during the rewarming period or after $\mathrm{CPB}$ termination.

\section{Definitions of Early Mortality, Stroke, and Adverse Outcomes}

Early mortality was defined as a death that occurred within the first 30 days postoperatively or before discharge from the hospital.

Stroke was defined as a recognized neurologic deficit documented clinically and radiologically (computed tomography or magnetic resonance imaging). Temporary neurologic disturbances that were not proved by imaging studies were not classified as a stroke. All strokes were classified as either embolic in nature or hypoperfusion related.

Several unfavorable outcomes of surgical treatment that could have been related to DHCA were classified as adverse outcomes, and all were analyzed together. These included early mortality, postoperative stroke, seizures, and acute renal failure.

\section{Long-Term Follow-up}

Long-term postoperative follow-up of the patients was conducted through our Aortic Institute Database and clinical visits, patient interviews, 
TABLE 1. Patient preoperative characteristics

\begin{tabular}{|c|c|c|c|c|}
\hline Variable & Overall & No adverse outcomes* & Adverse outcomes* & $P$ value \\
\hline Total patients & $490(100)$ & $467(95.3)$ & $23(4.7)$ & - \\
\hline Male sex & $303(61.8)$ & $291(62.3)$ & $11(47.8)$ & .328 \\
\hline \multicolumn{5}{|l|}{ Age (y) } \\
\hline Mean $\pm \mathrm{SD}$ & $62.7 \pm 13.5$ & $62.6 \pm 13.3$ & $65.6 \pm 18.4$ & .303 \\
\hline Range & $14-88$ & 24-88 & $14-82$ & \\
\hline \multicolumn{5}{|l|}{ Comorbidities and risk factors } \\
\hline Hypertension & $343(70.0)$ & $328(70.2)$ & $15(65.2)$ & .610 \\
\hline Tobacco smoking & $216(44.1)$ & $204(43.7)$ & $12(52.2)$ & .424 \\
\hline Dyslipidemia & $208(42.4)$ & $196(42.0)$ & $12(52.2)$ & .335 \\
\hline Coronary artery disease & $91(12.4)$ & $78(16.7)$ & $13(56.5)$ & $<.001 \dagger$ \\
\hline Pulmonary or respiratory disease & $58(11.8)$ & 54 (11.6) & $4(17.4)$ & .398 \\
\hline Neurologic deficit & $41(8.4)$ & $36(7.7)$ & $5(21.7)$ & $.018 \dagger$ \\
\hline Chronic kidney disease & $38(7.8)$ & $33(7.1)$ & $5(21.7)$ & $.010 \dagger$ \\
\hline Preoperative atrial fibrillation & $37(7.6)$ & $35(7.5)$ & $2(8.7)$ & .831 \\
\hline Diabetes & $32(6.5)$ & $30(6.4)$ & $2(8.7)$ & .669 \\
\hline Peripheral vascular disease & $18(3.7)$ & $14(3.0)$ & $4(17.4)$ & $<.001 \dagger$ \\
\hline Marfan syndrome & $9(1.8)$ & $9(1.9)$ & $0(0.0)$ & .501 \\
\hline Hyperthyroidism & $3(0.6)$ & $3(0.6)$ & $0(0.0)$ & .700 \\
\hline Hypothyroidism & $3(0.6)$ & $3(0.6)$ & $0(0.0)$ & .700 \\
\hline Positive family history & $111(22.7)$ & $104(22.3)$ & $7(30.4)$ & .362 \\
\hline Previous cardiac surgery & $71(14.5)$ & $63(13.5)$ & $8(34.8)$ & $.005 \dagger$ \\
\hline Previous aortic surgery & $65(13.3)$ & $59(12.6)$ & $6(26.1)$ & .063 \\
\hline \multicolumn{5}{|c|}{ Native aortic valve morphology $(\mathrm{n}=447)$} \\
\hline Tricuspid & $329(73.6)$ & $313(73.0)$ & $16(88.9)$ & .176 \\
\hline Bicuspid & $117(26.2)$ & $115(26.8)$ & $2(11.1)$ & .176 \\
\hline Unicuspid & $1(0.2)$ & $1(0.2)$ & $0(0.0)$ & 1.0 \\
\hline
\end{tabular}

Data presented as n (\%), unless noted otherwise. $S D$, Standard deviation. *Adverse outcomes included early mortality, stroke, seizures, and acute renal failure. $\dagger$ Statistically significant.

and the Social Security Death Index. Survival data were available for all 490 of the patients $(100 \%)$. The mean follow-up period was $60.9 \pm 38.5$ months.

\section{Statistical Analysis}

Statistical analysis was performed as described recently by Rizzo et al. ${ }^{19}$ Pearson's chi-square test and Fisher's exact test were used to compare proportions (categorical variables). The 2-tailed unpaired $t$ test was used

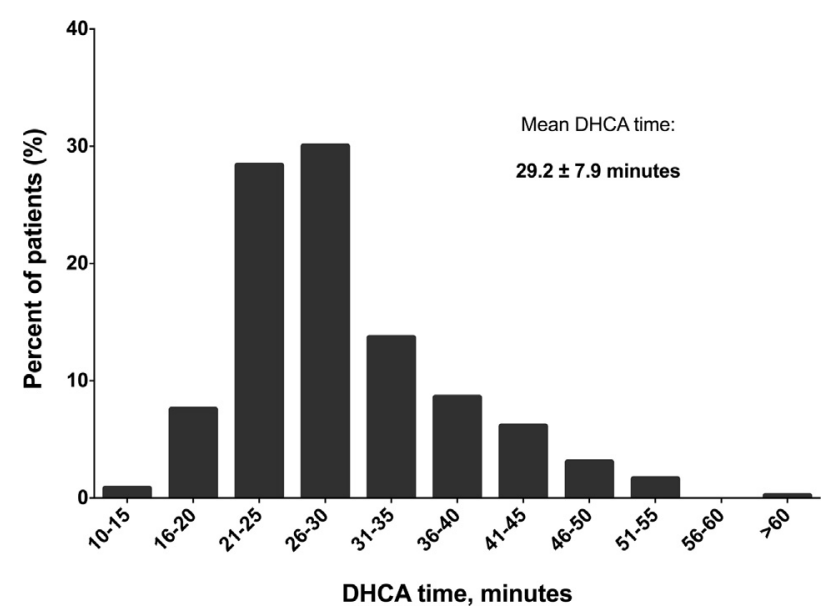

FIGURE 1. Distribution of deep hypothermic circulatory arrest (DHCA) time among 490 patients. to compare continuous variables. Bivariate analysis and multivariable logistic regression analysis were used to identify the predictors of adverse outcomes and was performed using Statistical Analysis Systems software (SAS Institute Inc, Cary, NC). Because of a low number of unfavorable outcomes, the multivariable analysis was able to accommodate only 3 predictor variables for the adverse outcomes analysis and 2 predictor variables for the early mortality analysis (to avoid overfitting). The Kaplan-Meier actuarial method was used to estimate long-term survival.

\section{RESULTS}

\section{Early Mortality}

Of the 490 patients, $12(2.4 \%)$ died within the first 30 days of the surgical intervention. Detailed information on all early deaths is listed in Table 3. Of these patients, $4(33.3 \%)$ had undergone a previous cardiac procedure, $7(58.3 \%)$ had developed aortic dissection, and $6(50.0 \%)$ underwent either urgent or emergency surgery (multiple categories for some patients). The duration of DHCA in this group of patients ranged from 26 to 50 minutes (mean, $34.6 \pm 6.9$ ). Four patients $(33.3 \%)$ experienced a stroke, 1 of which was related to cold agglutinin disease that had not been recognized preoperatively.

The early mortality among the patients operated electively was $1.4 \%$ (6 of 425). Five of these patients had been treated for an aortic aneurysm, and one had had chronic aortic dissection. One patient developed an 
TABLE 2. Operative data

\begin{tabular}{|c|c|c|c|c|}
\hline Variable & Overall & No adverse outcomes* & Adverse outcomes* & $P$ value \\
\hline Total patients & $490(100)$ & $467(95.3)$ & $23(4.7)$ & - \\
\hline Emergency or urgent procedures & $65(13.3)$ & $56(12.0)$ & $9(39.1)$ & $<.001 \dagger$ \\
\hline \multicolumn{5}{|l|}{ Primary indication for surgery (diagnosis) } \\
\hline Aneurysm & $417(85.1)$ & $403(86.3)$ & $14(60.9)$ & $.001 \dagger$ \\
\hline Dissection & $71(14.5)$ & $62(13.3)$ & $9(39.1)$ & $.001 \dagger$ \\
\hline \multicolumn{5}{|l|}{ CPB time (min) } \\
\hline Mean \pm SD & $157.1 \pm 34.6$ & $155.2 \pm 31.8$ & $197.6 \pm 58.3$ & $<.001 \dagger$ \\
\hline Range & 82-349 & 82-302 & 133-349 & - \\
\hline \multicolumn{5}{|l|}{ Aortic crossclamp time (min) } \\
\hline Mean \pm SD & $85.5 \pm 31.8$ & $85.1 \pm 32.0$ & $97.3 \pm 25.1$ & .080 \\
\hline Range & 4-176 & 4-176 & $42-140$ & - \\
\hline \multicolumn{5}{|l|}{ DHCA } \\
\hline \multicolumn{5}{|l|}{ Bladder temperature $\left({ }^{\circ} \mathrm{C}\right)$} \\
\hline Mean \pm SD & $18.7 \pm 0.7$ & $18.7 \pm 0.7$ & $18.1 \pm 0.8$ & $<.001 \dagger$ \\
\hline Range & $16-22$ & $16-22$ & $16-20$ & - \\
\hline \multicolumn{5}{|l|}{ DHCA duration (min) } \\
\hline Mean \pm SD & $29.2 \pm 7.9$ & $28.9 \pm 7.6$ & $36.3 \pm 10.2$ & $<.001 \dagger$ \\
\hline Range & $10-62$ & $10-54$ & $19-62$ & - \\
\hline \multicolumn{5}{|l|}{ Types of arch vessel anastomosis $(n=87)$} \\
\hline Two-vessel island & $57(65.6)$ & $53(66.3)$ & $4(57.1)$ & .688 \\
\hline Three-vessel island & $1(1.1)$ & $1(1.3)$ & $0(0.0)$ & 1.0 \\
\hline Branched arch graft or individual grafts to each vessel & $29(33.3)$ & $26(32.5)$ & $3(42.9)$ & .681 \\
\hline \multicolumn{5}{|l|}{ Associated cardiac procedures } \\
\hline Aortic valve replacement & $282(57.6)$ & $271(58.0)$ & $11(47.8)$ & .335 \\
\hline Mechanical & $168(34.3)$ & $161(34.5)$ & $7(30.4)$ & .689 \\
\hline Biologic (bioprosthesis) & $114(23.3)$ & $110(23.6)$ & $4(17.4)$ & .493 \\
\hline Aortic valve repair & $4(0.8)$ & $3(0.6)$ & $1(4.3)$ & .175 \\
\hline Aortic root replacement (composite graft) & $124(25.3)$ & $121(25.9)$ & $3(13.0)$ & .166 \\
\hline Coronary artery bypass grafting & $72(14.7)$ & $63(13.5)$ & $9(39.1)$ & $.001 \dagger$ \\
\hline Elephant trunk implantation & $55(11.2)$ & $52(11.1)$ & $3(13.0)$ & .777 \\
\hline Permanent pacemaker implantation & $28(5.7)$ & $28(6.0)$ & $0(0.0)$ & .227 \\
\hline Coronary interposition graft (modified Cabrol technique) & $18(3.7)$ & $16(3.4)$ & $2(8.7)$ & .190 \\
\hline Left atrial appendage ligation & $11(2.2)$ & $11(2.4)$ & $0(0.0)$ & .457 \\
\hline Innominate artery reconstruction & $7(1.4)$ & $6(1.3)$ & $1(4.3)$ & .227 \\
\hline Intra-aortic balloon pump placement & $6(1.2)$ & $1(0.2)$ & $5(21.7)$ & $<.001 \dagger$ \\
\hline Pericardial shunt with right atrium (Cabrol shunt) & $4(0.8)$ & $3(0.6)$ & $1(4.3)$ & .054 \\
\hline Atrial septal defect closure & $4(0.8)$ & $4(0.9)$ & $0(0.0)$ & .656 \\
\hline Mitral valve replacement & $3(0.6)$ & $3(0.6)$ & $0(0.0)$ & .700 \\
\hline Left ventricular assist device insertion & $2(0.4)$ & $1(0.2)$ & $1(4.3)$ & $.002 \dagger$ \\
\hline
\end{tabular}

Data presented as n (\%), unless noted otherwise. $C P B$, Cardiopulmonary bypass; $S D$, standard deviation; $D H C A$, deep hypothermic circulatory arrest. *Adverse outcomes included early mortality, stroke, seizures, and acute renal failure. †Statistically significant.

intraoperative type A dissection and subsequently experienced a stroke. Another patient required placement of a left ventricular assist device during aortic arch intervention, had a difficult postoperative course, and died during a second procedure (during the same hospitalization) for left ventricular assist device replacement.

\section{Early Morbidity}

The postoperative complications and their incidence are listed in Table 4. Atrial fibrillation was the most common postoperative complication, seen in 196 patients $(40.0 \%)$. However, at discharge from the hospital, atrial fibrillation persisted in only 54 patients $(11.0 \%)$. Re-exploration for bleeding was required in 22 patients $(4.5 \%)$. Seven patients developed seizures $(1.4 \%)$, and $6(1.2 \%)$ developed acute renal failure and required either dialysis or continuous venovenous hemofiltration.

\section{Postoperative Stroke Rate}

The overall postoperative stroke rate was $1.6 \%$ ( 8 of $490)$. Four of these patients $(50.0 \%)$ died during the first 30 days after the surgical intervention. Brain imaging in all patients with stroke was reviewed with a neuroradiologist. In 5 patients $(62.5 \%)$, the nature of the stroke was determined to be of embolic origin; the other 3 patients $(37.5 \%)$ had had a hypoperfusion-related stroke. Among 


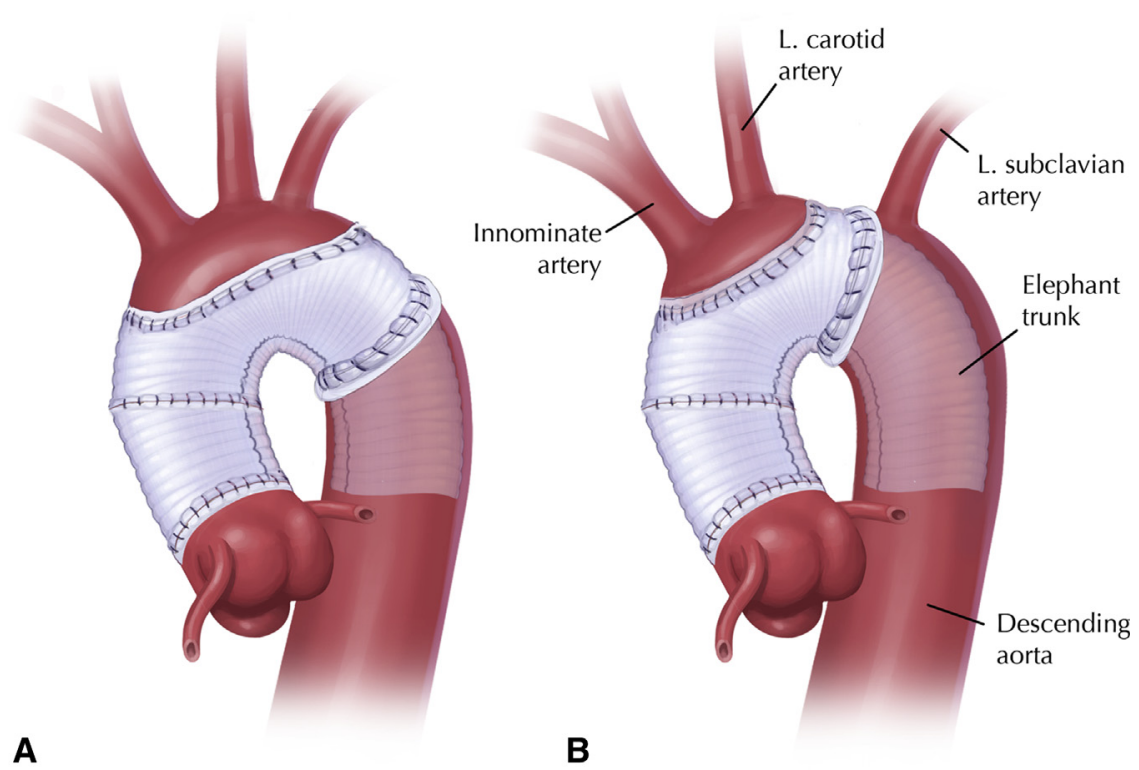

FIGURE 2. Techniques for aortic arch replacement. A, The 3-vessel Carrel patch technique. B, The 2-vessel Carrel patch technique, preferred at our institution.

the 5 patients who had developed embolic strokes, 2 had received retrograde arterial perfusion via the femoral artery $(40 \%)$, and 3 had received antegrade arterial perfusion via the distal aortic arch $(\mathrm{n}=2,40 \%)$ and right axillary artery $(\mathrm{n}=1,20 \%)$. The mean DHCA period among the patients who had experienced a stroke was $38.8 \pm 12.5$ minutes (range, 26-62). Stroke occurred in only 5 patients $(1.2 \%)$ who had undergone elective surgical treatment.

Three of the patients $(37.5 \%)$ with a postoperative stroke had had pre-existing neurologic conditions (previous strokes in 2 patients, 1 of whom had undergone previous carotid endarterectomy, 1 patient with speech problems after a Chiari malformation correction procedure). Three patients $(37.5 \%)$ had undergone previous cardiac interventions. One patient who developed a stroke was a 14-year-old male adolescent, with a history of heart transplantation at 2 months old for hypoplastic left heart syndrome, and later developed a major enlargement of the aortic arch in the native aortic region.

\section{Relationship of Stroke and DHCA Duration}

To determine the effect of the DHCA duration on the postoperative neurologic status, the patients were subdivided into 5 groups according to the DHCA time: 0 to 19 minutes in 21,20 to 29 minutes in 277,30 to 39 minutes in 131,40 to 49 minutes in 49 , and $\geq 50$ minutes in 12. The stroke rate was determined for each group separately. The relationship between the stroke rate and the DHCA duration is presented in Figure 3. The stroke rate in the 40- to 49-minute group was $2.0 \%$ ( 1 of 49 ), which was not significantly different from the stroke rate
$(1.2 \%, 5$ of 429$)$ for patients requiring $<40$ minutes $(P=.48)$. The overall stroke rate for patients requiring $<50$ minutes of DHCA was $1.3 \%$ (6 of 478), significantly different from the $16.7 \%$ ( 2 of 12 ) stroke rate in patients requiring $\geq 50$ minutes of DHCA $(P=.014)$. In the patients with $\geq 50$ minutes of DHCA, the cases of the 2 patients with cerebral events were extremely complex. One had undergone heart transplantation previously, was unstable hemodynamically perioperatively, and manifested diffuse hypoperfusion encephalopathy. The other patient developed an intraoperative aortic dissection during elective replacement surgery for aneurysm of the ascending aorta and total arch and experienced an embolic stroke. The brain events in these 2 patients might not have been related to the methods of brain protection. All 10 other patients with $\geq 50$ minutes DHCA experienced no cerebral events whatsoever.

\section{Bivariate and Multivariable Predictors of Adverse Outcomes}

Adverse outcomes were defined as the occurrence of early mortality $(\mathrm{n}=12,2.4 \%)$, stroke $(\mathrm{n}=8,1.6 \%)$, seizures $(n=7,1.4 \%)$, and acute renal failure $(n=6$, $1.2 \%)$. The total number of patients who experienced any of these adverse outcomes was $23(4.7 \%)$. The results of bivariate analysis are presented in Tables 1 and 2 . Bivariate analysis showed the presence of coronary artery disease $(P<.001)$, a pre-existing neurologic deficit $(P=.018)$, chronic kidney disease $(P=.010)$, peripheral vascular disease $(P<.001)$, and previous cardiac surgery $(P=.005)$ to be preoperative, pre-existing predictors of adverse outcomes. The rate of previous aortic surgery was 
TABLE 3. Cause of early death

\begin{tabular}{|c|c|c|c|c|c|c|c|c|c|c|c|}
\hline $\begin{array}{l}\text { Pt. } \\
\text { no. }\end{array}$ & $\begin{array}{r}\text { Age } \\
(\mathbf{y})\end{array}$ & Sex & Comorbidities & $\begin{array}{l}\text { Reope- } \\
\text { ration }\end{array}$ & $\begin{array}{c}\text { Surgical } \\
\text { acuity }\end{array}$ & $\begin{array}{c}\text { Primary } \\
\text { diagnosis }\end{array}$ & $\begin{array}{c}\text { Hemiarch } \\
\text { or total } \\
\text { arch }\end{array}$ & $\begin{array}{c}\text { Concomitant } \\
\text { procedures }\end{array}$ & $\begin{array}{l}\text { DHCA } \\
\text { time } \\
(\mathrm{min}) \\
\end{array}$ & $\begin{array}{c}\text { Postoperative } \\
\text { stroke } \\
\end{array}$ & Cause of death \\
\hline 1 & 57 & M & $\begin{array}{l}\text { HTN, DL, smoking, CKD } \\
\text { (kidney transplant } 17 \text { y } \\
\text { ago), CAD }(\mathrm{CABG} \times 4 \\
9 \text { y earlier) }\end{array}$ & Yes & Elective & Dissection & Hemiarch & $\begin{array}{l}\text { AVR, } \\
\text { interposition } \\
\text { graft to LCA, } \\
\text { LVAD }\end{array}$ & 31 & No & $\begin{array}{l}\text { LV failure } \\
\quad \text { (intraoperatively } \\
\text { during second } \\
\text { procedure for LVAD } \\
\text { replacement) }\end{array}$ \\
\hline 2 & 68 & $\mathrm{~F}$ & $\begin{array}{l}\text { HTN, DM, smoking, } \\
\text { COPD, CAD (PTCA } \\
1 \text { y earlier) }\end{array}$ & No & Emergency & Dissection & Hemiarch & - & 38 & Yes & $\begin{array}{l}\text { Multiple cerebral } \\
\text { infarcts (embolic), } \\
\text { thromboembolic } \\
\text { events to lower } \\
\text { extremities, } \\
\text { multiorgan failure }\end{array}$ \\
\hline 3 & 76 & M & $\begin{array}{l}\text { DL, CAD (post-MI, } \\
\quad \text { CABG } \times 324 \text { y earlier) }\end{array}$ & Yes & Emergency & Dissection & Hemiarch & - & 32 & Yes & $\begin{array}{l}\text { Cold agglutinin } \\
\text { disease, multiple } \\
\text { cerebral infarcts }\end{array}$ \\
\hline 4 & 58 & $\mathrm{~F}$ & $\begin{array}{l}\text { Smoking, } 5 \text { mo before } \\
\text { type B dissection and } \\
\text { thoracoabdominal } \\
\text { fenestration procedure }\end{array}$ & No & Emergency & Dissection & Hemiarch & $\begin{array}{c}\text { AV repair, shunt } \\
\text { to RA, IABP }\end{array}$ & 39 & No & $\begin{array}{l}\text { Malignant ventricular } \\
\text { arrhythmia } 9 \mathrm{~d} \\
\text { postoperatively }\end{array}$ \\
\hline 5 & 70 & M & $\begin{array}{l}\text { HTN, DL, smoking, CAD, } \\
\text { AF (warfarin) }\end{array}$ & No & Emergency & Dissection & Hemiarch & $\begin{array}{l}\text { AVR } \\
\text { (composite), } \\
\text { CABG } \times 1\end{array}$ & 32 & No & $\begin{array}{l}\text { Intraoperative death, } \\
\text { acute heart failure }\end{array}$ \\
\hline 6 & 77 & $\mathrm{~F}$ & $\begin{array}{l}\text { HTN, DL, neurologic } \\
\text { deficit (stroke, CAE } \\
3 \text { y earlier), COPD }\end{array}$ & No & Elective & Aneurysm & Total arch & $\mathrm{AVR}, \mathrm{CABG} \times 1$ & 26 & Yes & $\begin{array}{l}\text { Multiple cerebral } \\
\quad \text { infarcts (embolic) }\end{array}$ \\
\hline 7 & 81 & M & $\begin{array}{l}\text { HTN, DL, CKD, CAD, } \\
\text { arch branching anomaly } \\
\text { (bovine arch) }\end{array}$ & No & Elective & Aneurysm & Hemiarch & AVR, $\mathrm{CABG} \times 3$ & 30 & No & $\begin{array}{l}\text { Acute renal failure, } \\
\text { pulmonary edema }\end{array}$ \\
\hline 8 & 61 & M & $\begin{array}{l}\text { HTN, DL, DM, smoking, } \\
\text { CKD, neurologic deficit } \\
\text { (strokes with right-sided } \\
\text { deficit, TIAs) }\end{array}$ & No & Emergency & Dissection & Total arch & $\begin{array}{l}\text { AVR, ET, } \\
\text { innominate } \\
\text { reconstruction }\end{array}$ & 44 & No & $\begin{array}{l}\text { Ventricular arrhythmia } \\
3 \mathrm{~d} \text { postoperatively } \\
\text { during PV procedure } \\
\text { for ischemic limb }\end{array}$ \\
\hline 9 & 67 & $\mathrm{~F}$ & HTN & No & Elective & Aneurysm & Hemiarch & AVR & 28 & No & $\begin{array}{l}\text { Ventricular tachycardia } \\
\text { and cardiac arrest } \\
5 \mathrm{~d} \text { postoperatively }\end{array}$ \\
\hline 10 & 82 & M & $\begin{array}{l}\text { HTN, smoking, CAD } \\
(\mathrm{CABG} \times 2 \text { and AVR } \\
16 \text { y earlier), occluded } \\
\text { vein graft to CMA, TI }\end{array}$ & Yes & Elective & Aneurysm & Hemiarch & $\begin{array}{l}\text { Interposition } \\
\text { graft to RCA, } \\
\text { IABP }\end{array}$ & 32 & No & $\begin{array}{l}\text { Ventricular arrhythmia } \\
\text { (pre-existing) }\end{array}$ \\
\hline 11 & 69 & $\mathrm{~F}$ & $\begin{array}{l}\text { HTN, smoking, arch } \\
\text { branching anomaly } \\
\text { (bovine arch) }\end{array}$ & No & Elective & Aneurysm & Total arch & - & 50 & Yes & $\begin{array}{l}\text { Intraoperative type A } \\
\text { dissection, cerebral } \\
\text { infarct (embolic) }\end{array}$ \\
\hline 12 & 80 & $\mathrm{~F}$ & $\begin{array}{l}\text { HTN, smoking, CAD, } \\
\text { status: after type A } \\
\text { dissection } 10 \text { y earlier } \\
\text { with ascending aortic } \\
\text { replacement }\end{array}$ & Yes & Urgent & Dissection & Hemiarch & $\begin{array}{l}\text { AVR, } C A B G \times 2, \\
\text { IABP }\end{array}$ & 33 & No & $\begin{array}{l}\text { Right ventricular } \\
\text { failure, acute } \\
\text { respiratory failure }\end{array}$ \\
\hline
\end{tabular}

Pt. no., Patient number; $D H C A$, deep hypothermic circulatory arrest; $M$, male; $H T N$, hypertension; $D L$, dyslipidemia; $C K D$, chronic kidney disease; $C A D$, coronary artery disease; $C A B G$, coronary artery bypass grafting; $A V R$, aortic valve replacement; $L C A$, left coronary artery; $L V A D$, left ventricular assist device; $F$, female; $D M$, diabetes mellitus; $C O P D$, chronic obstructive pulmonary disease; $P T C A$, percutaneous transluminal coronary angioplasty; $M I$, myocardial infarction; $A V$, aortic valve; $R A$, right atrium; $I A B P$, intra-aortic balloon pump; $A F$, atrial fibrillation; $C A E$, carotid endarterectomy; $T I A$, transient ischemic attack; $E T$, elephant trunk; $P V$, peripheral vascular; $C M A$, circumflex marginal artery; $T I$, tricuspid insufficiency; $R C A$, right coronary artery. 
TABLE 4. Postoperative complications

\begin{tabular}{lc}
\hline \multicolumn{1}{c}{ Variable } & n (\%) \\
\hline Atrial fibrillation & $196(40.0)$ \\
Pulmonary complications (parenchymal) & $27(5.5)$ \\
Prolonged ventilation $(>48 \mathrm{~h})$ & $23(4.7)$ \\
Reexploration for bleeding & $22(4.5)$ \\
Other arrhythmias & $18(3.7)$ \\
Pleural complications (pneumothorax/effusion) & $12(2.4)$ \\
Stroke & $8(1.6)$ \\
Wound complications & $7(1.4)$ \\
Seizures & $7(1.4)$ \\
Acute renal failure requiring dialysis or CVVH & $6(1.2)$ \\
Pericardial effusion & $5(1.0)$ \\
Pacemaker implantation & $4(0.8)$ \\
Percutaneous endoscopic gastrostomy tube placement & $4(0.8)$ \\
Tracheostomy & $3(0.6)$ \\
Venous thromboembolism & $3(0.6)$ \\
Systemic infections & $2(0.4)$ \\
Low cardiac output & $2(0.4)$ \\
Postoperative intra-aortic balloon pump placement & $1(0.2)$ \\
Myocardial ischemia & $1(0.2)$ \\
Mesenteric hemorrhage & $1(0.2)$ \\
\hline
\end{tabular}

$\mathrm{CVVH}$, Continuous venovenous hemofiltration.

also greater in the adverse outcomes group $(26.1 \%)$ than in no adverse outcomes group (12.6\%), although no significant difference was observed. In terms of the operative data, aortic dissection as the primary diagnosis and indication for surgery $(P=.001)$, an urgent or emergency surgical intervention $(P<.001)$, concomitant coronary artery bypass grafting $(P=.001)$, CPB duration $(P<.001)$, and DHCA duration $(P<.001)$ were also predictors of adverse outcomes.

Multivariable analysis was used to determine the predictors of adverse outcomes (Table 5) and showed that the extent of surgery (hemiarch vs total arch replacement) was not a predictor of adverse outcomes (odds ratio [OR], $1.11 \pm 0.60 ; P=.844$ ). However, aortic dissection as the primary indication for surgery (OR, 3.59 $\pm 1.72 ; P=.008)$ and DHCA duration of $>50$ minutes $(\mathrm{OR}, 5.11 \pm 4.01 ; P=.038)$ were predictors of adverse outcomes.

Multivariable analysis was also used to determine the predictors of early mortality (Table 5). Again, the extent of surgery was not a predictor of mortality (OR, $0.67 \pm 0.48 ; P=.580$ ); however, aortic dissection as the indication for surgery was a strong predictor of early mortality $(\mathrm{OR}, 14.58 \pm 9.48 ; P<.001)$.

\section{Long-Term Survival}

Long-term postoperative follow-up of hospital survivors revealed that 75 patients $(15.7 \%)$ had died late (excluding the early deaths), having lived an average of $41.7 \pm 34.4$ months (range, 1-130) postoperatively before death, and 403 patients $(84.3 \%)$ were still alive. The actuarial survival for patients who had undergone aortic arch surgery with DHCA was $93.2 \% \pm 1.1 \%, 89.4 \% \pm 1.4 \%$,

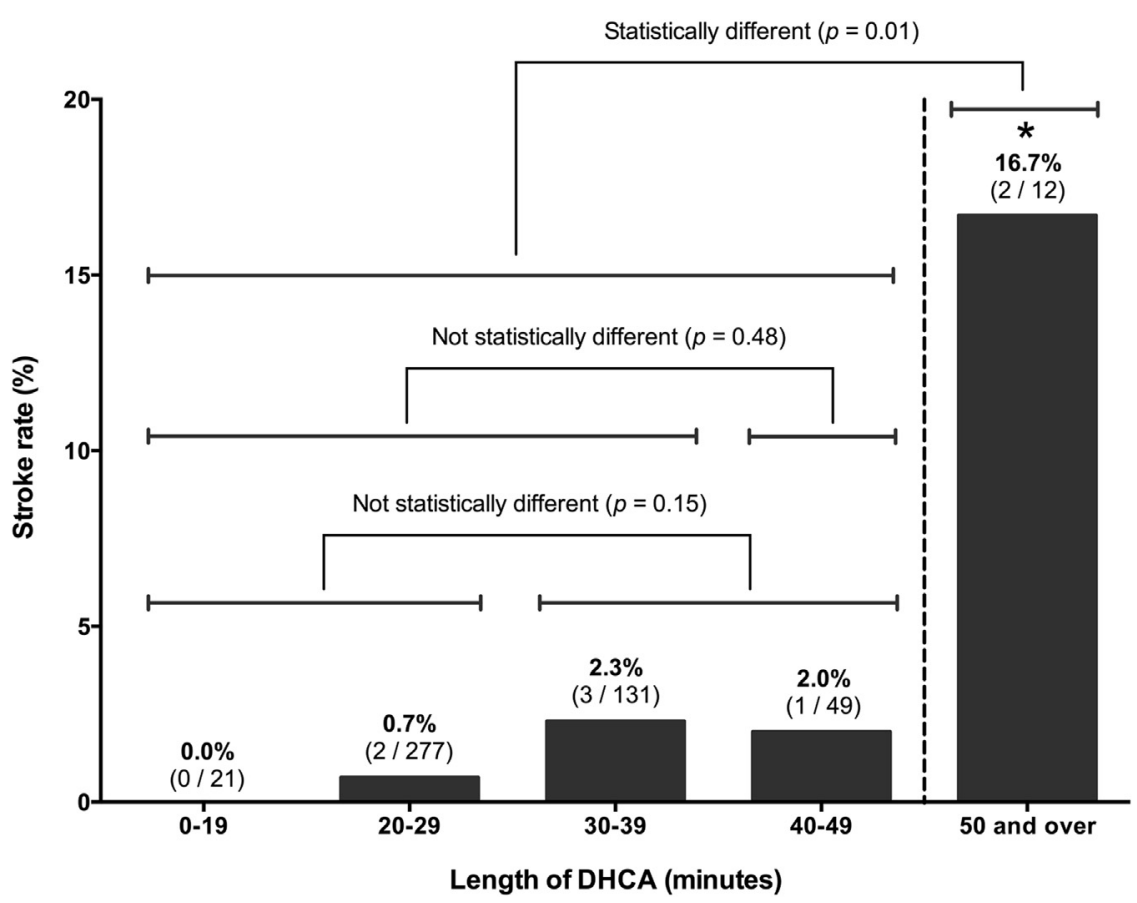

FIGURE 3. Relationship between postoperative stroke rates and deep hypothermic circulatory arrest (DHCA) duration during aortic arch surgery. The number of patients in each DHCA time category is indicted. Note that the column for "50 and over" was determined from only 2 strokes (in patients with extremely complex cases) among only 12 patients with DHCA of this duration. See text for details. 
TABLE 5. Multivariate analysis of predictors of adverse outcomes and early mortality

\begin{tabular}{|c|c|c|c|}
\hline Variable & $\mathbf{O R} \pm \mathrm{SE}$ & $95 \% \mathrm{CI}$ & $\begin{array}{c}P \\
\text { value }\end{array}$ \\
\hline \multicolumn{4}{|l|}{ Risk of developing an adverse outcome } \\
\hline $\begin{array}{l}\text { Extent of surgery (total arch } \\
\text { vs hemiarch replacement) }\end{array}$ & $1.11 \pm 0.60$ & $0.38-3.22$ & .844 \\
\hline DHCA duration $>50 \mathrm{~min}$ & $5.11 \pm 4.01$ & $1.10-23.80$ & $.038 *$ \\
\hline $\begin{array}{l}\text { Dissection as primary indication } \\
\text { for surgery }\end{array}$ & $3.59 \pm 1.72$ & $1.40-9.17$ & $.008^{*}$ \\
\hline \multicolumn{4}{|l|}{ Risk of early mortality } \\
\hline $\begin{array}{l}\text { Extent of surgery (total arch } \\
\text { vs hemiarch replacement) }\end{array}$ & $0.67 \pm 0.48$ & $0.16-2.76$ & .580 \\
\hline $\begin{array}{l}\text { Dissection as primary indication } \\
\text { for surgery }\end{array}$ & $14.58 \pm 9.48$ & $4.07-52.18$ & $<.001^{*}$ \\
\hline
\end{tabular}

$84.8 \% \pm 1.8 \%$, and $72.1 \% \pm 3.6 \%$ at $1,3,5$, and 10 years, respectively (Figure 4).

\section{DISCUSSION}

In the present study, we have shown that DHCA is a safe and effective technique for neuroprotection during surgery of the aortic arch. At our institution, we have accumulated significant experience with straight DHCA during the past 25 years, and we believe that almost all arch replacements can be performed safely with DHCA. Our results also provide evidence that at experienced centers up to 50 minutes of circulatory arrest under hypothermic conditions can be considered safe, although we have found that most arch operations can be performed within 40 minutes.

\section{Two-Vessel Island Technique for Arch Vessel Reimplantation}

Over the years, several techniques for reimplantation of the great vessels have evolved, including the 3-vessel Carrel patch $^{20}$ (Figure 2, A), 3-branched grafts, ${ }^{21,22}$ 4-branched grafts, ${ }^{23}$ and, most recently, the hybrid 4-branched graft combined with a stent graft at the distal end. ${ }^{24}$

Our preferred technique for arch vessel reimplantation has used a 2-vessel Carrel patch that includes just the innominate artery and left common carotid artery (Figure 2, B). The advantages of using the 2-vessel patch are the reduction in the length of the anastomosis line, enabling the surgeon to complete the head-vessel anastomosis within a shorter period, and complete access in case additional hemostatic sutures are necessary for the pedicle or distal elephant trunk anastomosis. The left subclavian artery is reanastomosed at a later stage in the procedure, usually during the rewarming period. It can also be replaced at a later second-stage elephant trunk procedure through a left thoracotomy.

In the present patient series, the 2-vessel island technique was used in $65.6 \%$ of total arch replacement cases. However, sometimes using a 2 -vessel patch is not feasible, for example cases in which either the innominate or left common carotid artery is aneurysmal or severely dissected or in which a risk of repeat dissection or embolization from atherosclerotic or calcium debris exists. In these cases, we have used one of the multibranch techniques to reattach the head vessels; however, even this more complex procedure can be accomplished within 40 minutes of DHCA.

In most cases, we will also supplement the arch replacement procedure with implantation of the elephant

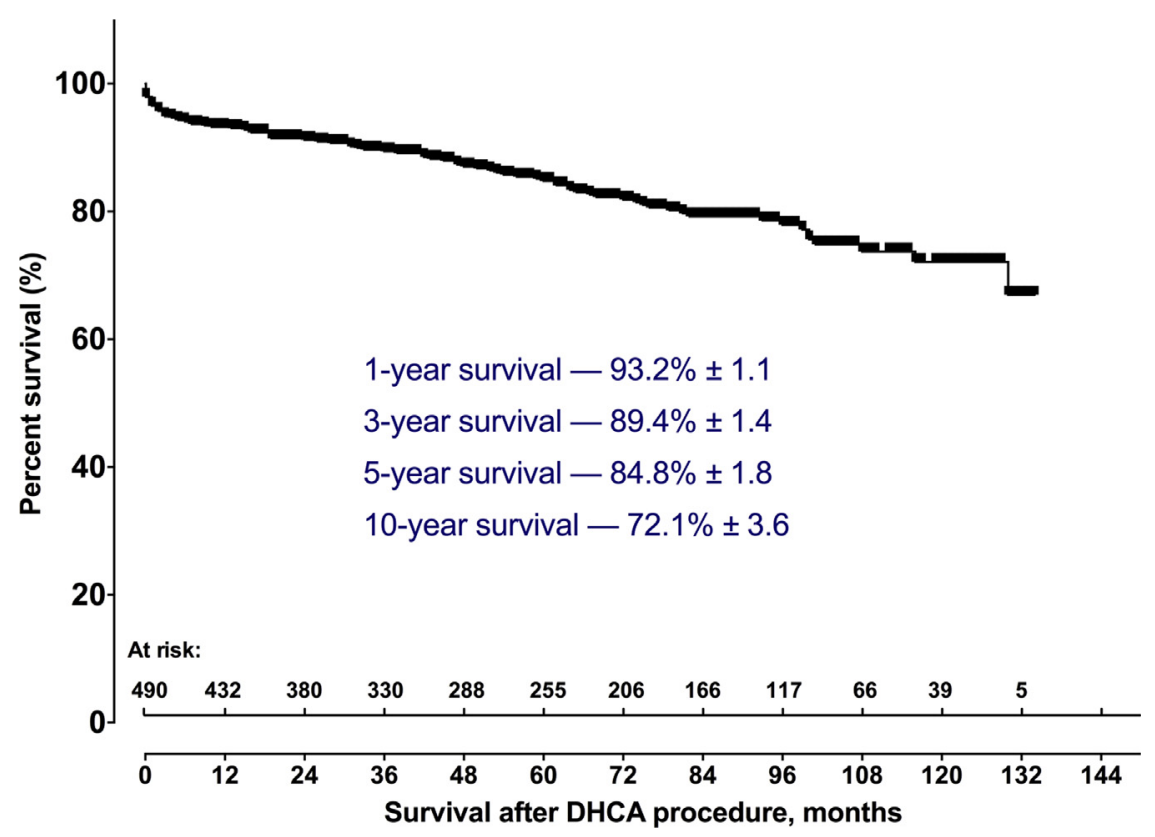

FIGURE 4. Kaplan-Meier survival curve for patients receiving deep hypothermic circulatory arrest ( $D H C A$ ). 
trunk graft (performed in $63.2 \%$ of all total arch replacements). This has proved extremely useful should a second-stage procedure involving the descending aorta (open or endovascular) be needed. Traditionally, the distal arch anastomosis with the elephant trunk graft is created distal to the take off of the left subclavian artery. However, recently, we have started creating the distal anastomosis between the origins of the left common carotid and left subclavian arteries. This approach provides better access to the suture lines, should inspection for the purpose of hemostasis be required at anastomosis completion. With the traditional approach, access to the distal suture line in the case of bleeding can be impossible.

\section{Early Mortality and Morbidity}

The present study revealed low levels of early mortality and morbidity in patients undergoing surgery under DHCA. The overall mortality in our series was $2.4 \%$, and the elective mortality was $1.4 \%$. This is comparable with our previously reported results in an earlier, smaller series. ${ }^{12}$ We studied all 12 patients who had died within the first 30 days of the surgical intervention in great detail to determine the cause of death (Table 3). It appears that only 4 of the 12 deaths (33\%) were brain related and could potentially be associated with the method of cerebral protection. Other deaths occurred for reasons that were most likely not related to the method of brain protection. Multivariate analysis revealed aortic dissection to be a strong predictor of early mortality. The most recent large-scale studies that evaluated other cerebral protection techniques have reported mortality levels to be in the range of $3.2 \%$ to $11.6 \%$ for $\mathrm{ACP}$ and $4.1 \%$ to $17.0 \%$ for RCP (a detailed review of the data can be found in Chau and colleagues ${ }^{17}$ and Ziganshin and Elefteriades ${ }^{25}$ ). The present results with straight DHCA compared very favorably with these reports for ACP and RCP.

The overall postoperative stroke rate in our study was $1.6 \%$, and for the elective cases was $1.2 \%$. Of the 8 strokes, $5(62.5 \%)$ were embolic in nature and 3 were related to hypoperfusion. This echoes the findings of our previous study. ${ }^{12}$ That approximately two thirds of the strokes were embolic suggests that they were most likely not related to any inadequacy of DHCA as a cerebral protection strategy; rather, the occurrence of embolic strokes represented the severity of the underlying arteriosclerotic disease in these patients. The same largescale studies that reported the mortality rates for patients undergoing aortic arch surgery with adjunctive perfusion techniques also reported the postoperative stroke rate: $2.2 \%$ to $9.6 \%$ for ACP and $2.9 \%$ to $9.0 \%$ for RCP. ${ }^{17,25}$ Comparing our postoperative mortality and stroke rates with these results, we have concluded that straight DHCA is not inferior to other neuroprotection strategies that rely on perfusion adjuncts.
An analysis of the potential DHCA-related postoperative complications (early mortality, postoperative stroke, seizures, and acute renal failure) showed that these adverse outcomes tended to develop in patients with significant pre-existing comorbidities or who had required emergency surgery. In our study, these patients had significantly greater rates of neurologic comorbidities, coronary artery disease, chronic kidney disease, and peripheral vascular disease (Table 1) and required more complex surgical interventions (Table 2). Also, the patients were much more likely to develop adverse outcomes if they had previously undergone open heart surgery.

These findings are suggestive that the adverse outcomes in these patients were most likely not from an inadequacy of DHCA as a neuroprotector, but rather resulted from the complexity of the surgical procedure and the severity of the underlying conditions, which would increase the risk of any surgical intervention, even without DHCA.

\section{Safe DHCA Duration}

There is no consensus in the literature in terms of the duration of DHCA that can be considered safe. In an early report, Svensson and colleagues ${ }^{11}$ showed that the incidence of postoperative stroke increased in cases that required $>40$ minutes of DHCA. Another study showed that as long as 60 minutes of DHCA could be considered safe. ${ }^{26}$ More recent publications, however, have argued that only 20 to 25 minutes of DHCA can be considered safe. ${ }^{16,27,28}$ In our previous report, we identified 40 minutes as the cutoff point, beyond which caution would be warranted. ${ }^{12}$

In the present study, to determine the DHCA duration that can be considered safe from the neuroprotective standpoint, we analyzed the occurrence of stroke in relationship to the DHCA duration (Figure 3). We found that the stroke rate increased significantly in patients with a DHCA duration $\geq 50$ minutes $(16.7 \%)$. In the patients with a DHCA period of 40 to 49 minutes, the stroke rate was $2.0 \%$. This finding was also supported by the results of multivariable analysis that determined that DHCA times $\geq 50$ minutes to be significant predictors of early mortality and adverse outcomes (Table 5). However, the stroke rate in patients with $\geq 50$ minutes DHCA was determined from only 2 strokes (of only 12 patients who had required $\geq 50$ minutes of DHCA). Thus, the 50-minute threshold should best be "taken with a grain of salt." Also, 1 of these strokes was embolic and, thus, not directly attributable to the method of brain protection. One of these patients had undergone previous heart transplantation and was hemodynamically unstable perioperatively, and the other had developed intraoperative aortic dissection during replacement surgery for an ascending and arch aneurysm. The other 10 patients with $\geq 50$ minutes of DHCA developed no cerebral problems or complications. 
Although we still consider the 40-minute mark to be the cutoff point, below which DHCA is invariably safe, the results of the present study have provided evidence that even longer times of up to 50 minutes can be considered quite safe. We believe that the present study adds an important additional 10-minute "cushion period" in the armamentarium of the surgeon that allows extra time for more complex procedures should extended periods of circulatory arrest be needed.

\section{Neurocognitive Recovery}

Several studies that evaluated the postoperative neurocognitive function of patients undergoing surgery with DHCA reported its negative effect on neurologic function. ${ }^{16,27-29}$ In contrast, Svensson and colleagues ${ }^{30}$ found DHCA to be the superior method for preserving neurocognitive function. Our group previously reported that in patients with high cognitive needs for their professions (ie, physicians, lawyers, administrators, accountants), DHCA had no effect on their reported cognition or work performance postoperatively. ${ }^{31}$ Furthermore, in a study recently published by our group, we were able to show that the overall neurocognitive function was well preserved among patients operated under DHCA and was not different between patients undergoing surgery with and without DHCA. ${ }^{32}$ One of the recent studies of neurocognitive function from the Mount Sinai group revealed that DHCA (14-40 minutes) or isolated CPB (70-369 minutes) did not have an adverse effect on postoperative cognitive function. However, selective cerebral perfusion (range, 39-83 minutes) was a significant predictor of a decline in performance on memory and language tests. ${ }^{33}$

\section{Comparison of DHCA and Other Cerebral Protection Techniques}

Our group has previously published several reports with a detailed literature review comparing various cerebral protection techniques. ${ }^{6,17,25}$ It is clear that all 3 techniques currently in use (straight DHCA, ACP, and RCP) are viable options for cerebral protection during aortic arch surgery, and their use is largely dependent on institutional and individual surgeon preference. However, each technique has advantages and limitations. ${ }^{25}$ RCP can be helpful in flushing the cerebral vasculature of toxic metabolic products and embolic debris; however, this technique has become increasingly less popular because not much oxygen actually reaches the neuronal tissue. ${ }^{34} \mathrm{ACP}$ is the most physiologic technique. Because it delivers oxygenrich blood to the brain, ACP currently ranks as the most popular and widespread technique. ACP is very useful when $>50$ minutes might be needed to complete the procedure. However, uncertainties remain regarding the number of vessels that need to be perfused and the appropriate flow rates to deliver enough oxygen but not cause cerebral edema. ${ }^{35}$
All these factors make the simplicity and elegance of straight DHCA especially appealing. According to a recent poll reported by Ziganshin, ${ }^{36} 48 \%$ of experts use straight DHCA. The data from the present study has provided justification for such continued use of DHCA. No manipulation of the head vessels is required, no cerebral edema occurs, and a branched perfusion system is not needed with DHCA. These characteristics are especially useful in the setting of emergency procedures, such as acute aortic dissection, that can spare little time for setting up adjunctive perfusion. DHCA provides a clean, bloodless operative field, with no intrusive clamps or adjunctive perfusion cannulas.

\section{Study Limitations}

One of the limitations of the present study was its retrospective nature. That we identified only 23 patients with any major adverse outcomes (ie, early mortality, stroke, seizures, and acute renal failure) permitted us statistically to use only 2 or 3 variables to establish associations on multivariable analysis. A comparatively low number of patients requiring $>40$ minutes and an even lower number of patients requiring $>50$ minutes of DHCA was another limitation of the present study. Yet another limitation of the study was that it was center and surgeon specific, and the results might be difficult to replicate in a different setting.

\section{CONCLUSIONS}

Straight DHCA is a safe and effective technique of cerebral protection for most interventions involving the aortic arch. Hemiarch operations and straightforward total arch operations that can safely be completed within 40 to 50 minutes of DHCA are especially well suited to straight DHCA. We recommend DHCA as the first choice technique of cerebral protection. Although neither DHCA, RCP, nor $\mathrm{ACP}$ has unequivocally shown significant superior over the others, the results of the present study have provided evidence that straight DHCA is at least not inferior to other neuroprotection strategies and can produce excellent clinical results.

\section{References}

1. De Bakey ME, Crawford ES, Cooley DA, Morris GC Jr. Successful resection of fusiform aneurysm of aortic arch with replacement by homograft. Surg Gynecol Obstet. 1957;105:657-64.

2. Debakey ME, Henly WS, Cooley DA, Crawford ES, Morris GC Jr, Beall AC Jr. Aneurysms of the aortic arch: factors influencing operative risk. Surg Clin North Am. 1962;42:1543-54.

3. Elefteriades JA. What is the best method for brain protection in surgery of the aortic arch? Straight DHCA. Cardiol Clin. 2010;28:381-7.

4. Ueda Y. What is the best method for brain protection in surgery of the aortic arch? Retrograde cerebral perfusion. Cardiol Clin. 2010;28:371-9.

5. Bachet J. What is the best method for brain protection in surgery of the aortic arch? Selective antegrade cerebral perfusion. Cardiol Clin. 2010;28: 389-401. 
6. Ziganshin B, Elefteriades JA. Does straight deep hypothermic circulatory arrest suffice for brain preservation in aortic surgery? Semin Thorac Cardiovasc Surg. 2010;22:291-301.

7. Griepp RB, Stinson EB, Hollingsworth JF, Buehler D. Prosthetic replacement of the aortic arch. J Thorac Cardiovasc Surg. 1975;70:1051-63.

8. Ergin MA, O'Connor J, Guinto R, Griepp RB. Experience with profound hypothermia and circulatory arrest in the treatment of aneurysms of the aortic arch: aortic arch replacement for acute arch dissections. J Thorac Cardiovasc Surg. 1982;84:649-55.

9. Erecinska M, Thoresen M, Silver IA. Effects of hypothermia on energy metabolism in mammalian central nervous system. J Cereb Blood Flow Metab. 2003;23:513-30.

10. Gonzalez-Ibarra FP, Varon J, Lopez-Meza EG. Therapeutic hypothermia: critical review of the molecular mechanisms of action. Front Neurol. 2011; 2:4.

11. Svensson LG, Crawford ES, Hess KR, Coselli JS, Raskin S, Shenaq SA, et al. Deep hypothermia with circulatory arrest: determinants of stroke and early mortality in 656 patients. J Thorac Cardiovasc Surg. 1993;106:19-28; discussion 28-31.

12. Gega A, Rizzo JA, Johnson MH, Tranquilli M, Farkas EA, Elefteriades JA. Straight deep hypothermic arrest: experience in 394 patients supports its effectiveness as a sole means of brain preservation. Ann Thorac Surg. 2007;84: 759-66; discussion 66-7.

13. Elmistekawy EM, Rubens FD. Deep hypothermic circulatory arrest: alternative strategies for cerebral perfusion. A review article. Perfusion. 2011;26(suppl 1): 27-34.

14. Matalanis G, Koirala RS, Shi WY, Hayward PA, McCall PR. Branch-first aortic arch replacement with no circulatory arrest or deep hypothermia. J Thorac Cardiovasc Surg. 2011;142:809-15.

15. Ergin MA, Uysal S, Reich DL, Apaydin A, Lansman SL, McCullough JN, et al. Temporary neurological dysfunction after deep hypothermic circulatory arrest: a clinical marker of long-term functional deficit. Ann Thorac Surg. 1999;67: 1887-90; discussion 91-4.

16. Immer FF, Lippeck C, Barmettler H, Berdat PA, Eckstein FS, Kipfer B, et al. Improvement of quality of life after surgery on the thoracic aorta: effect of antegrade cerebral perfusion and short duration of deep hypothermic circulatory arrest. Circulation. 2004;110:II250-5.

17. Chau KH, Ziganshin BA, Elefteriades JA. Deep hypothermic circulatory arrest: real-life suspended animation. Prog Cardiovasc Dis. 2013;56:81-91.

18. Ayyash B, Tranquilli M, Elefteriades JA. Femoral artery cannulation for thoracic aortic surgery: safe under transesophageal echocardiographic control. J Thorac Cardiovasc Surg. 2011;142:1478-81.

19. Rizzo JA, Chen J, Fang H, Ziganshin BA, Elefteriades JA. Statistical challenges in identifying risk factors for aortic disease. Aorta. 2014;2: 45-55.

20. Crawford ES, Saleh SA. Transverse aortic arch aneurysm: improved results of treatment employing new modifications of aortic reconstruction and hypothermic cerebral circulatory arrest. Ann Surg. 1981;194:180-8.

21. Spielvogel D, Etz CD, Silovitz D, Lansman SL, Griepp RB. Aortic arch replacement with a trifurcated graft. Ann Thorac Surg. 2007;83:S791-5; discussion S824-31.

22. Lemaire SA, Weldon SA, Coselli JS. Total aortic arch replacement: current approach using the trifurcated graft technique. Ann Cardiothorac Surg. 2013;2: 347-52.

23. Sakamoto S, Matsubara J, Nagayoshi Y, Nishizawa H, Takeuchi K, Nonaka T, et al. Clinical results of aortic arch replacement using a four branched prosthetic graft. J Cardiovasc Surg (Torino). 2003;44:751-5.

24. Shrestha M, Pichlmaier M, Martens A, Hagl C, Khaladj N, Haverich A. Total aortic arch replacement with a novel four-branched frozen elephant trunk graft: first-in-man results. Eur J Cardiothorac Surg. 2013;43:406-10.

25. Ziganshin BA, Elefteriades JA. Deep hypothermic circulatory arrest. Ann Cardiothorac Surg. 2013;2:303-15.

26. Ergin MA, Galla JD, Lansman SL, Quintana C, Bodian C, Griepp RB. Hypothermic circulatory arrest in operations on the thoracic aorta: determinants of operative mortality and neurologic outcome. J Thorac Cardiovasc Surg. 1994; 107:788-97; discussion 97-9.

27. Reich DL, Uysal S, Sliwinski M, Ergin MA, Kahn RA, Konstadt SN, et al. Neuropsychologic outcome after deep hypothermic circulatory arrest in adults. J Thorac Cardiovasc Surg. 1999;117:156-63.

28. Uysal S, Mazzeffi M, Lin HM, Fischer GW, Griepp RB, Adams DH, et al. Internet-based assessment of postoperative neurocognitive function in cardiac and thoracic aortic surgery patients. J Thorac Cardiovasc Surg. 2011;141: $777-81$.

29. Harrington DK, Bonser M, Moss A, Heafield MT, Riddoch MJ, Bonser RS Neuropsychometric outcome following aortic arch surgery: a prospective randomized trial of retrograde cerebral perfusion. J Thorac Cardiovasc Surg. 2003; 126:638-44.

30. Svensson LG, Nadolny EM, Penney DL, Jacobson J, Kimmel WA, Entrup MH, et al. Prospective randomized neurocognitive and S-100 study of hypothermic circulatory arrest, retrograde brain perfusion, and antegrade brain perfusion for aortic arch operations. Ann Thorac Surg. 2001;71:1905-12.

31. Percy A, Widman S, Rizzo JA, Tranquilli M, Elefteriades JA. Deep hypothermic circulatory arrest in patients with high cognitive needs: full preservation of cognitive abilities. Ann Thorac Surg. 2009;87:117-23.

32. Chau KH, Friedman T, Tranquilli M, Elefteriades JA. Deep hypothermic circulatory arrest effectively preserves neurocognitive function. Ann Thorac Surg. 2013;96:1553-9.

33. Uysal S, Lin HM, Fischer GW, Di Luozzo G, Reich DL. Selective cerebral perfusion for thoracic aortic surgery: association with neurocognitive outcome. J Thorac Cardiovasc Surg. 2012;143:1205-12.

34. Reich DL, Uysal S, Ergin MA, Griepp RB. Retrograde cerebral perfusion as a method of neuroprotection during thoracic aortic surgery. Ann Thorac Surg. 2001;72:1774-82

35. Pacini D, Di Marco L, Leone A, Tonon C, Pettinato C, Fonti C, et al. Cerebral functions and metabolism after antegrade selective cerebral perfusion in aortic arch surgery. Eur J Cardiothorac Surg. 2010;37:1322-31.

36. Ziganshin BA. Which method of cerebral protection do you prefer to use for aortic arch surgery? AORTA. 2013;1:69-70.

\section{Discussion}

Dr Joseph D. Schmoker (Burlington, Vt). Congratulations on your outstanding results.

Both the mortality rate of $2.4 \%$ and the stroke rate of $1.6 \%$ in this large series of patients over the span of 11 years is highly commendable. You have improved on your previous stroke rate of $3.1 \%$ reported in 2007. These results helped to reinforce a role for DHCA when performed properly in the treatment of noncomplex aortic arch pathology when the circulatory arrest times are $<40$ minutes, such as was the case in your series and inclusive of almost $90 \%$ of your patients.

However, the data interpretation becomes more problematic when analyzing the risk of stroke with longer arrest times. In your previous series, the stroke rate was 13\% if the arrest time was $>40$ minutes. In the present study, the mean arrest time for those patients with stroke was 39 minutes, and the stroke rate increased to $17 \%$ when the arrest time was $>50$ minutes. From these aggregate data, evidence exists of a strong trend toward an increased stroke risk after 40 minutes with DHCA alone.

I take issue with your interpretation that your embolic strokes had no association with the circulatory arrest duration. Emboli superimposed on cold ischemia can add insult to the vulnerable at-risk tissue, the penumbra, and certainly could contribute to a more profound deficit. In that fashion, the circulatory arrest time could have an effect on stroke severity related to emboli.

This brings me to 3 questions, and we will take each individually. The definition of stroke used in this project (ie, the requirement for both a clinical deficit and positive imaging study findings) might serve to underreport the incidence if careful imaging was not performed in all patients with a deficit, which would include those with seizures and other more prolonged temporary neurologic dysfunction. 
The current acceptable definition of stroke is either a permanent deficit alone, whether a focal deficit or a generalized deficit such as a gait disturbance or Parkinsonism, or any deficit, however, brief or extended associated with a positive finding on imaging.

Did you follow this definition, and, if so, did all patients with extended temporary neurologic dysfunction or seizures undergo appropriate imaging?

Dr Ziganshin. Thank you very much for your comments and questions, Dr Schmoker.

In terms of the first question, we used the following definition of stroke: a clinically and radiologically (computed tomography [CT] or magnetic resonance imaging) recognized neurologic deficit. All patients with a persisting deficit underwent $\mathrm{CT}$, and, if the deficit persisted and the CT findings were negative, they underwent magnetic resonance imaging.

In terms of temporary and neurologic deficits—we found these very difficult to classify and detect because, in our experience, most patients who could potentially be considered as having temporary neurologic deficits had confusion as their postoperative complication.

Confusion, as we know, can occur not only after procedures involving DHCA, but also any other procedures requiring cardiopulmonary bypass.

If the neurologic deficits persisted in these patients, they subsequently underwent imaging studies. However, in our study, all patients classified as not having a stroke were discharged home without any neurologic deficits whatsoever.

Dr Schmoker. Thank you. You also answered my second question regarding the insensitivity of CT for embolic or ischemic stroke early after surgery and the need for follow-up with magnetic resonance imaging.

My last question pertains to a concern about peripheral cannulation and retrograde perfusion in patients with risk factors for atheroma; $80 \%$ of your patients were perfused from the groin. Although you engaged more central perfusion if evidence was found of atheroma in the descending thoracic aorta on imaging, it appears that no policy was in place to obtain abdominal imaging preoperatively. It is possible that the embolic strokes could have occurred from undetected debris dislodged from the atheromatous abdominal or iliofemoral systems by retrograde perfusion.

Knowing that 5 patients had embolic stroke and 3 patients had hypoperfusion as their stroke etiology, what was the breakdown between the central and peripheral cannulation in these 2 groups? Thank you.

Dr Ziganshin. Thank you very much for your question, Dr Schmoker.

That is a very important point, and we do acknowledge that we could not safely state that in all patients abdominal imaging was performed.

However, it is a policy at our institution to perform abdominal CT imaging for all patients undergoing elective surgery.

Of course, in an emergency setting, it is not possible to obtain a CT image, and then we have to rely on intraoperative transesophageal echocardiography to detect atheromatous debris.

However, as a second point, in our experience, it is very rare to have severe atherosclerotic disease in the abdominal aorta and to have absolutely no involvement of the descending aorta. That is why we believe our approach is safe.

In terms of the breakdown between central and peripheral cannulation, I have it here on the slide. Ten percent of the patients in the entire study cohort received right axillary cannulation, $9.4 \%$ received distal arch cannulation, and only $1 \%$ received innominate artery cannulation. All other patients were perfused via the femoral artery.

In terms of the patients with embolic strokes: the total was 5, 2 had been cannulated via the femoral artery, 2 had undergone distal arch cannulation, and 1 patient had undergone right axillary cannulation. Thus, we can see that retrograde flow was only used in 2 of these patients with embolic stroke.

Dr Schmoker. Thank you.

Dr Joseph S. Coselli (Houston, Tex). Quick question. Did you have any deaths in your series that were unable to be evaluated neurologically, and if so, how did you include those in your analysis?

Dr Ziganshin. We had 1 case of an intraoperative death. That was a case of an acute type A dissection, and we were unable to include that patient in our neurologic analysis; however, that patient was included in the study as an early death.

Dr Scott A. LeMaire (Houston, Tex). The rewarming strategy can also influence the incidence of neurologic complications. Would you tell us about your rewarming strategy, particularly because you used bladder temperatures. What temperature do you rewarm to? What is the rate of rewarming?

Dr Ziganshin. The rewarming time is usually about 1 hour. We do not hurry with rewarming. We take as much time as needed, especially for patients who are obese or overweight. Such cases require a significant amount of rewarming time. The difference in temperature of the perfusate is about $10^{\circ} \mathrm{C}$ always, and we rewarm until about $34^{\circ} \mathrm{C}$.

Dr LeMaire. Thirty-four, okay. Thank you.

Dr Ourania Preventza (Houston, Tex). Congratulations for this excellent study. I would like to ask you, what was your transfusion rate during the aortic arch surgery?

Dr Preventza. All your cases were performed with straight DHCA. What was your transfusion rate during the aortic arch surgery?

Dr Ziganshin. We did not look at this parameter specifically in light of this study, but from our clinical experience, the transfusion rate for our aortic interventions was no different than that for any other cardiac procedures performed at our center.

The re-exploration rate for bleeding was $4.5 \%$.

Dr Preventza. Okay. Thank you.

Dr Burkhart Zipfel (Berlin, Germany). I have a question on your double artery island technique.

Dr Zipfel. How do you handle the left subclavian artery then, do you just occlude it?

Dr Ziganshin. The technique illustrated on the slide is the preferred technique that we use at our institution. The elephant trunk graft is usually placed, and we leave it relatively long if we anticipate a second-stage procedure. If a second-stage procedure is needed, that means that the descending aorta is relatively dilated, and there is enough room for retrograde flow to the left subclavian artery. In our experience, we have not seen complications related to the left subclavian artery. 
However, there is a technique that we use at the end of the procedure to determine whether the flow to the left subclavian artery is compromised. Because the left subclavian artery has a radial catheter in it, we check to see whether the central pressure is different from the pressure in the radial artery. If it is, we perform a bypass during the first-stage procedure. If it is not, we leave the left subclavian artery and manage it during the second-stage procedure, when this is much easier and safer to do.

Access to The Journal of Thoracic and Cardiovascular Surgery Online is reserved for print subscribers!

Full-text access to The Journal of Thoracic and Cardiovascular Surgery Online is available for all print subscribers. To activate your individual online subscription, please visit The Journal of Thoracic and Cardiovascular Surgery Online, point your browser to http://www.mosby.com/jtcvs, follow the prompts to activate your online access, and follow the instructions. To activate your account, you will need your subscriber account number, which you can find on your mailing label (note: the number of digits in your subscriber account number varies from 6 to 10). See the example below in which the subscriber account number has been circled:

\section{Sample mailing label}

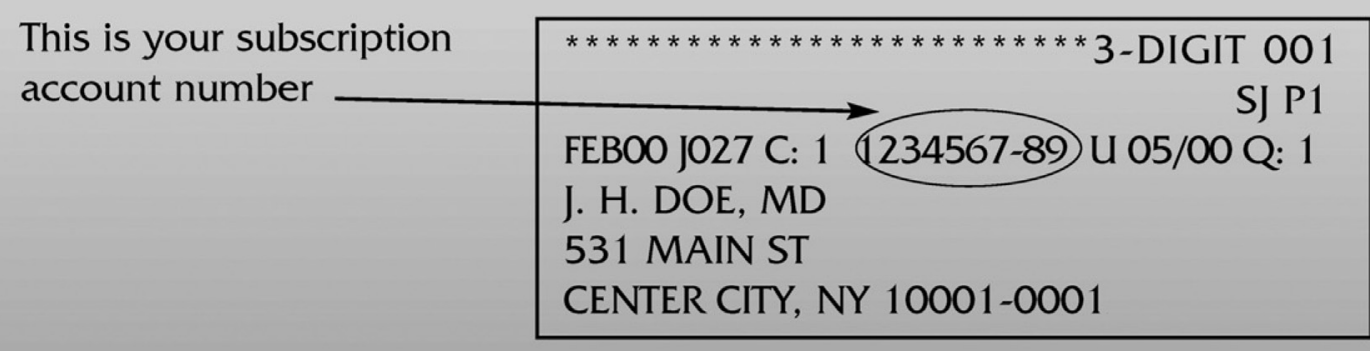

Personal subscriptions to The Journal of Thoracic and Cardiovascular Surgery Online are for individual use only and may not be transferred. Use of The Journal of Thoracic and Cardiovascular Surgery Online is subject to agreement to the terms and conditions as indicated online. 